\title{
Rata de Magdalena: un importante mamífero mexicano, poco conocido y en riesgo de extinción
}

\author{
Fernando A. Cervantes Reza y Pamela Montaño Sosa
}

\section{Resumen}

La rata de Magdalena (Xenomys nelsoni) es una especie de roedor endémico de México, de importancia ecológica, evolutiva y en conservación. Desafortunadamente, es poco conocida y se encuentra en peligro de extinción. Habita únicamente en las selvas secas de la vertiente del Pacífico mexicano en Jalisco y Colima, y últimamente se le ha registrado sólo en la Reserva de la Biósfera Chamela-Cuixmala. Es un mamífero de hábitos arborícolas, solitario, nocturno, que se alimenta principalmente de hojas, yemas y frutos. En la actualidad, se efectúan estudios sobre su distribución geográfica, morfología y genética molecular para dar a conocer su existencia y características principales; así como contribuir en acciones para su conservación.

Palabras clave: rata de Magdalena, Cricetidae, Rodentia, endémico, selva seca, vertiente del Pacífico mexicana.

\section{MAGDALENA RAT: AN IMPORTANT MEXICAN MAMMAL, LITTLE KNOWN AND AT RISK OF EXTINCTION}

\begin{abstract}
The Magdalena Rat (Xenomys nelsoni) is a species of rodent endemic to Mexico, of ecological, evolutionary and conservation importance. Unfortunately, it is little known and threatened with extinction. It only inhabits the dry jungles of the Mexican Pacific slope in Jalisco and Colima and lately it has only been reported in the Chamela-Cuixmala Biosphere Reserve. It is a mammal of arboreal habits, solitary, nocturnal, which feeds mainly on leaves, buds and fruits. Currently, studies are being carried out on its geographical distribution, morphology and molecular genetics, in order to make its existence and main characteristics known, as well as to contribute with actions for its conservation.
\end{abstract}

Keywords: Magdalena rat, Cricetidae, Rodentia, endemic, dry forest, Mexican Pacific slope.

DOI: http://doi.org/10.22201/codeic.16076079e.2019.v20n5.a2 
"Rata de Magdalena: un importante mamífero mexicano, poco conocido y en riesgo de extinción"

\section{Fernando A. Cervantes Reza}

fac@ib.unam.mx

Obtuvo su licenciatura en Biología y una maestría en Ciencias en la Universidad Nacional Autónoma de México (UNAM), y otra maestría en Ciencias, así como su doctorado en Ciencias en la University of Kansas. Fue profesor titular de la Universidad Autónoma Metropolitana (UAM), Iztapalapa, y actualmente es investigador y curador de mamíferos del Instituto de Biología, UNAM. Su línea de trabajo es la sistemática, ecología y conservación de especies endémicas y en riesgo de extinción de mamíferos mexicanos. Promueve las colecciones biológicas, sus bases de datos y su exhibición. Dirige tesis de grado y posgrado, e imparte docencia a nivel licenciatura y posgrado sobre mamíferos, biodiversidad, taxonomía y conservación. Es miembro del Sistema Nacional de Investigadores y de la Academia Mexicana de Ciencias.

\section{Pamela Montaño Sosa}

pamm mos18@hotmail.com

Obtuvo su licenciatura en Biología en la UAM, unidad Iztapalapa. Actualmente efectúa una investigación de campo sobre mamíferos de zonas tropicales en el sureste de México. Asimismo, colabora en actividades de curación e investigación de la Colección Nacional de Mamíferos del Instituto de Biología, UNAM. Su principal tema de interés radica en la protección de los ecosistemas con énfasis en la conservación de la fauna silvestre, especialmente de los mamíferos endémicos y poco conocidos del país.

\section{Introducción}

El roedor Xenomys nelsoni o rata de Magdalena, es una especie distintiva de mamífero, que, desafortunadamente, es poco o nada conocida en su ambiente natural (ver figura 1). Existen diversos motivos por los cuales debemos conocer a esta especie: sólo existe en una pequeña región de México, está asociada a las continuamente perturbadas selvas secas (bosques tropicales caducifolios) del Pacífico mexicano y, lamentablemente, se encuentra en una de las categorías de riesgo de extinción reconocidas por el gobierno mexicano. Asimismo, los biólogos han reportado que se trata de un mamífero emblemático que, aunque de tamaño pequeño y difícilmente visible en su hábitat natural, es de gran importancia ecológica, biogeográfica y evolutiva. Además, debemos conocer a la rata de Magdalena porque, como otras especies amenazadas de México como el jaguar, el tapir, el berrendo y el lobo mexicano, también contribuye a la sumatoria de especies que colocan a México como un país con uno de los niveles más elevados de biodiversidad. La rata de Magdalena es, por lo tanto, una especie más de nuestra fauna silvestre que debe ser conocida por académicos, estudiantes, comunidades locales, organizaciones no gubernamentales y los distintos niveles de gobierno, para contribuir en acciones para su conservación.

¿Quién es, entonces, Xenomys nelsoni?, ¿cómo es y en dónde habita?, ¿cuáles son los factores que amenazan su supervivencia?, ¿qué podemos hacę al respecto? Lo expondremos a continuación. 
Figura 1. Ejemplar macho adulto de la rata de Magdalena (Xenomys nelsoni) registrado en una selva seca (bosque tropical caducifolio) de la región de la costa de Chamela, Jalisco, México, en marzo de 2005 (Cervantes, Ramos, Vargas y Montaño, 2019a).

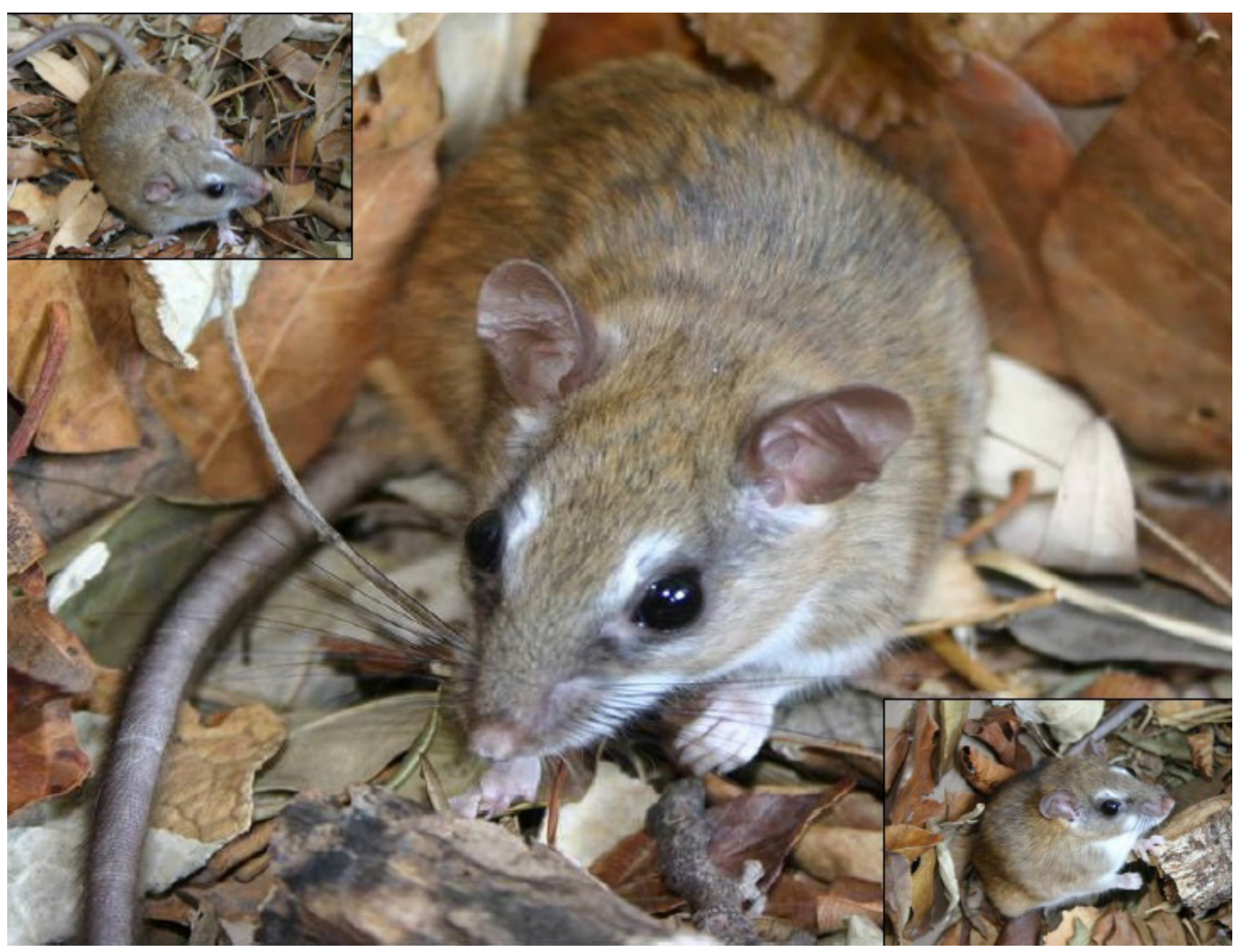

Xenomys nelsoni pertenece al orden Rodentia, uno de los grupos de mamíferos más abundantes del mundo en cuanto a número de individuos y de especies (casi 2 300; Tzab y Macswiney, 2014: 12). Asimismo, con excepción del continente australiano, los roedores se encuentran en casi todas partes del mundo y habitan prácticamente en todo tipo de hábitat natural conocido. De acuerdo con esto, los roedores en México suman poco menos de 50\% de las especies conocidas de mamíferos silvestres (casi 550) y se les encuentra tanto en ecosistemas templados como tropicales. Sin embargo, existen especies de roedores endémicas de México, esto es, las que sólo se encuentran dentro de los límites geográficos del país. Las áreas geográficas que se distinguen por su alto número de este tipo de especies son las selvas secas (bosques tropicales caducifolios) del occidente, que cubren la vertiente del Pacífico mexicano (ver figura 2; Ceballos y Martínez, 2010: 123). En esta región podemos encontrar diversas especies de los ocho géneros de roedores endémicos que hay en México, entre los cuales destaca Xenomys, el cual contiene solamente una especie (ver figura 3). 
Figura 2. Riqueza de especies de mamíferos de las selvas secas mexicanas, incluyendo la fracción de especies que habitan sólo en México y la proporción de taxa en alguna categoría de riesgo de extinción (imagen tomada de Ceballos y Martínez, 2010: 123)
Figura 3. Vista dorsal comparativa de pieles de ejemplares de colección científica de algunos roedores endémicos (excepto Neotoma albigula), con presencia en la vertiente del Pacífico mexicano. De arriba hacia abajo: Nelsonia goldmani, Neotoma albigula, Xenomys nelsoni y Hodomys alleni (Cervantes y Hernández, 2016a).

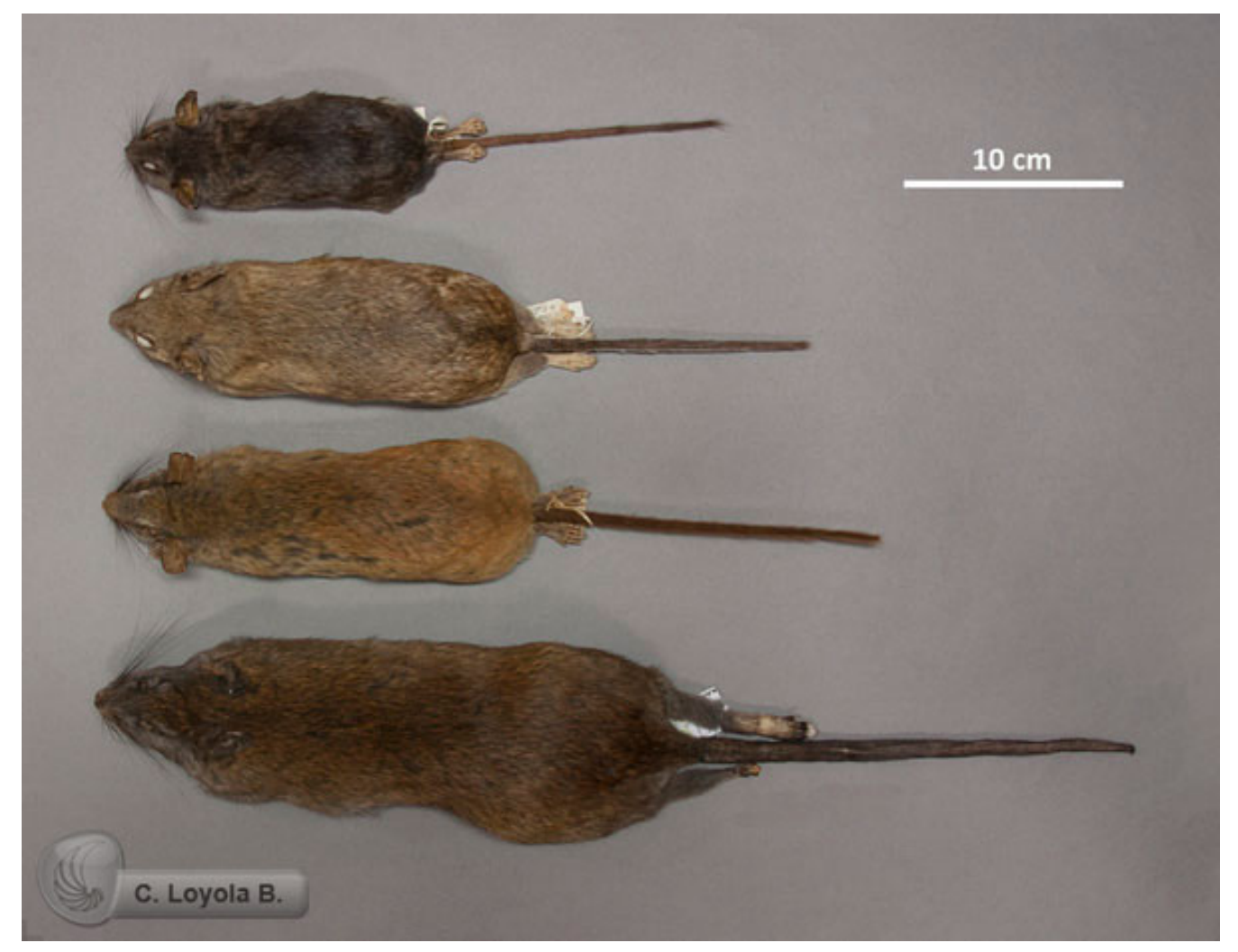




\section{Distribución geográfica}

La rata de Magdalena (Xenomys nelsoni) sólo se puede encontrar en una zona relativamente pequeña de la costa tropical de los estados de Jalisco y Colima (ver figura 4; Ceballos y Martínez, 2010: 125). Los biólogos han reportado su presencia sólo en tres áreas: Armería y Pueblo Juárez (Colima), así como en Chamela (Jalisco). Afortunadamente, esta última área forma parte de la Reserva de la Biosfera Chamela-Cuixmala (RBCC), en el municipio de la Huerta, aproximadamente a 120 km al norte de Manzanillo, Colima, entre el margen norte del Río Cuitzmala y el Arroyo Chamela.
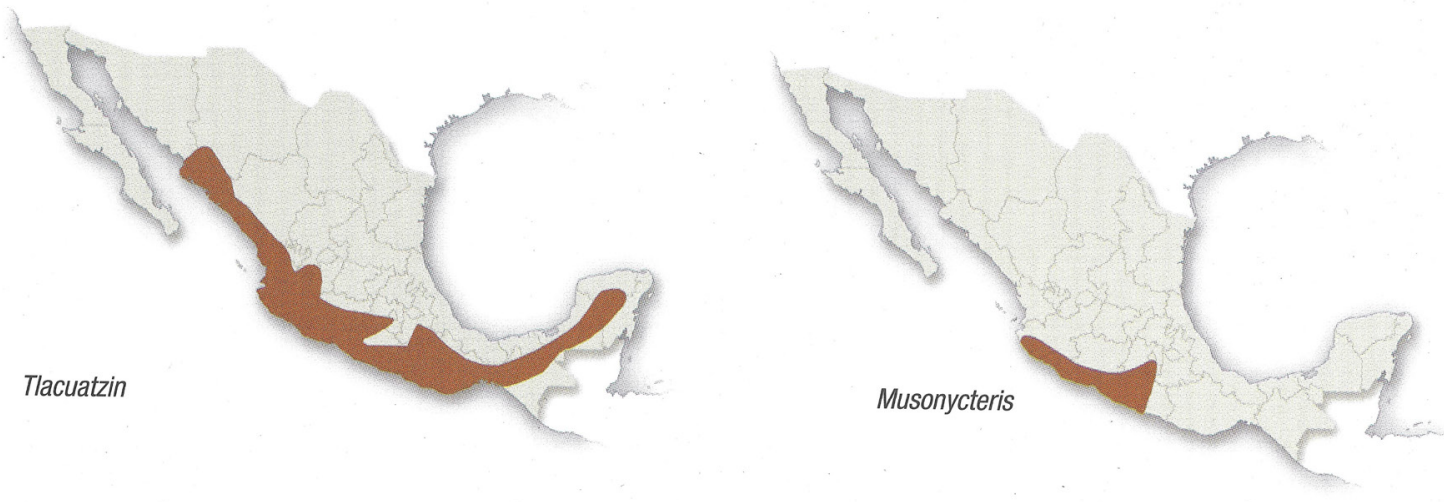

Figura 4. Distribución geográfica de algunas especies de mamíferos pequeños endémicos de las selvas secas mexicanas, incluyendo la rata de Magdalena (Xenomys nelsoni). Imagen tomada de Ceballos y Martínez, 2010: 125.
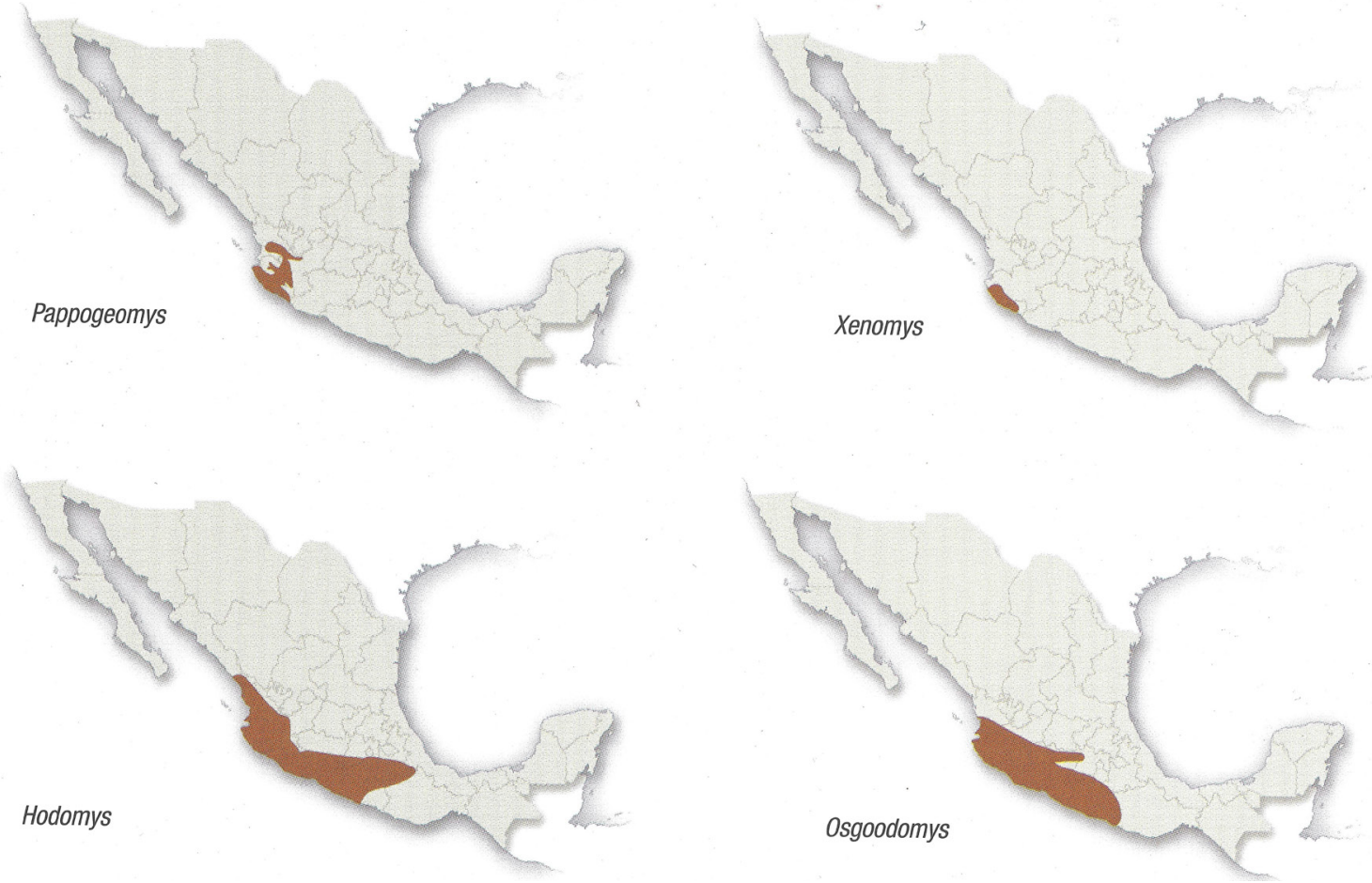

Dicha especie tiene una de las distribuciones geográficas más pequeñas de todos los mamíferos de México. Biológicamente es interesante que las áreas de distribución de las especies endémicas de las selvas secas son menores que el promedio de todos los mamíferos de México (Ceballos y Martínez, 2010: 128). 
Figura 5. A) Vista de la selva seca (bosque tropical caducifolio) de las cercanías de la población El Tuito, Municipio Cabo Corrientes, Jalisco, sitio probable de la presencia de la Rata de Magdalena (Xenomys nelsoni; fotografía de M. López Zamora). B) Marcha mensual del clima de los alrededores de Chamela, Jalisco, región donde más se ha registrado la presencia de $X$. nelsoni en su habitat natural (imagen tomada y modificada de Hayden et al. 2010: 238).
Sin embargo, esta condición representa una situación difícil para la conservación de la biodiversidad pues hay que proteger, aunque pequeñas, muchas áreas dispersas y sin corredores para su conexión.

\section{Clima y hábitat}

Xenomys nelsoni habita en la selva baja caducifolia o selva seca, donde las especies arbóreas normalmente miden entre 5 y 10 m (ver figura 5A). Este ambiente se caracteriza por una fuerte estacionalidad climática, donde la época húmeda se concentra prácticamente en cuatro meses, de junio a septiembre, y el resto del año la mayoría de los árboles pierden sus hojas por un período de cinco a siete meses (ver figura 5B; Hayden, Greene y Quesada, 2010: 238).
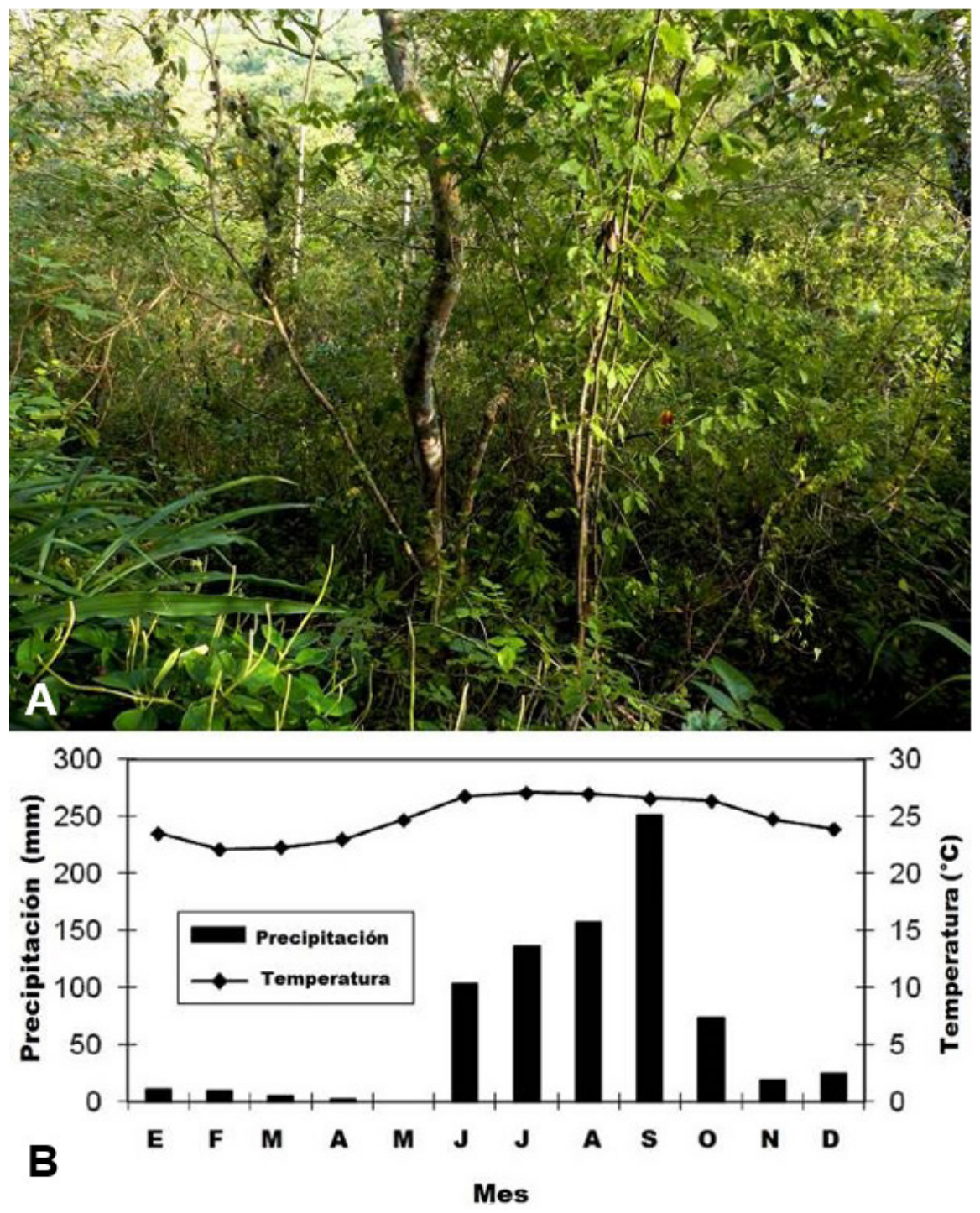
Figura 6. Rata de Magdalena (Xenomys nelsoni), que muestra la fisionomía típica de roedor. Los tonos de color y su combinación, así como sus manchas particulares la hace muy distintiva a la vista (Cervantes et al. 2019b).
Es notable que numerosas especies de árboles nunca presenten hojas y flores simultáneamente, produciendo abundantes flores durante la sequía (Bullock y Solís, 1990: 27). Los biólogos han registrado la presencia de individuos de la rata de Magdalena, por lo general, en áreas con una alta densidad de árboles y con follaje denso y cerrado, principalmente en las copas de los árboles. En particular, han detectado su presencia en árboles de anona (Annona reticulata), palo mulato (Bursera simaruba) y hule (Castilla elastica; Schaldach, 1960: 4).

\section{Características generales}

La apariencia de la rata de Magdalena (Xenomys nelsoni) es similar a la de otras especies de rata. La longitud, en adultos, de su cuerpo y cola juntos es de 250 a 350 mm (Miranda, 2002: 439; ver figura 6). El color del pelaje del dorso varía de canela-marrón a amarillo claro-marrón y es pálido en la cabeza y brillante sobre las caderas; muchos pelos tienen puntas negras. Las partes inferiores son de color blanco cremoso (Ceballos y Miranda, 2000: 185); las orejas son redondeadas y miden de 20 a $24 \mathrm{~mm}$ de longitud. Una de sus características distintivas son las manchas blancas que tiene arriba de cada ojo y detrás y en la base de cada oreja. La cola es peluda, sin escamas y casi del mismo tamaño que el resto del cuerpo (145-175 mm). Su peso varía de 90 a 130 g en los adultos, mientras que en los subadultos de alrededor de 65 g y los jóvenes de 40 g.

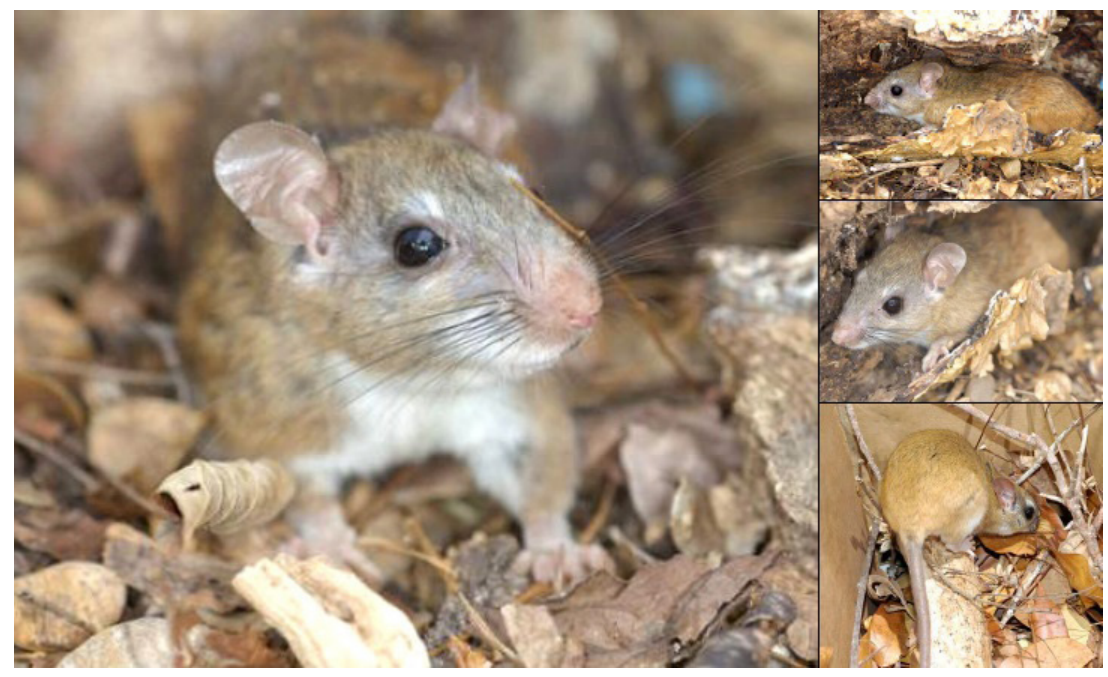

Excepto por el tamaño y el peso, no se conocen otras diferencias entre sexos o categorías de edad. El cráneo de este roedor es característico, donde destaca el hueso timpánico (que contiene a los oídos medio e interno) relativamente grande e inflado, con su eje longitudinal casi paralelo al eje del cráneo; el borde supraorbital es levantado y prominente (ver figura 7A). Además, la superficie del molar inferior 3 (el más posterior de la mandíbula) tiene una forma diagnóstica en forma de "S" (ver figura 7B). Las medidas craneales de adultos, al combinar 
Figura 7. Cráneo y pieza dental de ejemplares adultos de colección científica de la rata de Magdalena (Xenomys nelsoni). A) Vista dorsal donde se aprecia el borde supraorbital prominente sobre cada una de las órbitas oculares (Cervantes y Hernández, 2010a). B) Vista ventral que muestra las bulas timpánicas típicas que alojan a cada uno de los oídos de este roedor (Cervantes et al., 2010b).

C) Acercamiento de la vista superior del molar inferior 3 de la mandíbula derecha, que muestra el patrón de esmalte diagnóstico de la especie (Cervantes, Castañón, Sánchez, Vargas y Hortelano, 2016).

datos de ambos sexos, son: longitud mayor del cráneo, 40.5-44.6 mm; longitud condilobasal, 35.3-39.6 mm; ancho cigomático 20.2-21.9 mm; longitud de los nasales 14.1-15.9 mm; y longitud de la hilera superior de dientes 8.0-9.0 mm (Ceballos y Miranda, 2000: 185).

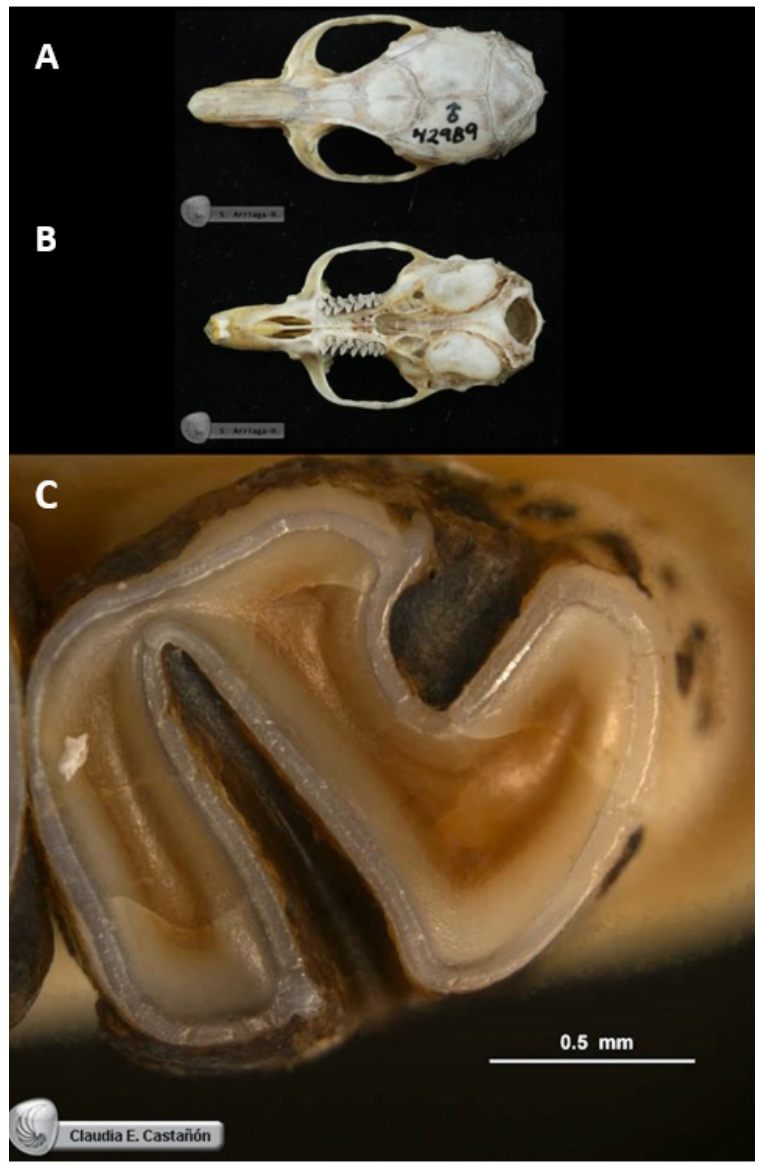

\section{Crecimiento, reproducción, alimentación, comportamiento}

Xenomys nelsoni es un roedor de hábitos principalmente arborícolas (ver figura 8A). Si bien ha sido capturado en trampas dispuestas sobre la superficie del suelo, los biólogos consideran que la mayor parte del tiempo la pasa entre el follaje de los árboles, a una altura de entre 1 y 4 metros. Este mamífero utiliza huecos y oquedades en las ramas y tronco de los árboles como refugio, así como enramadas y conglomerados de follaje. Se desconoce el impacto que tiene la época seca del año cuando disminuye considerablemente el follaje de los árboles. 
Figura 8. A) La rata de Magdalena (Xenomys nelsoni) se ha especializado en vivir principalmente en la copa de los árboles de las selvas secas de la vertiente del Pacífico mexicano, aprovechando huecos y oquedades como refugio y sitio de nidificación (fotografía de Gustavo Zaragoza). B) Como la mayoría de los roedores, es una especie de hábitos nocturnos (fotografía de Diana Fuentes R.).

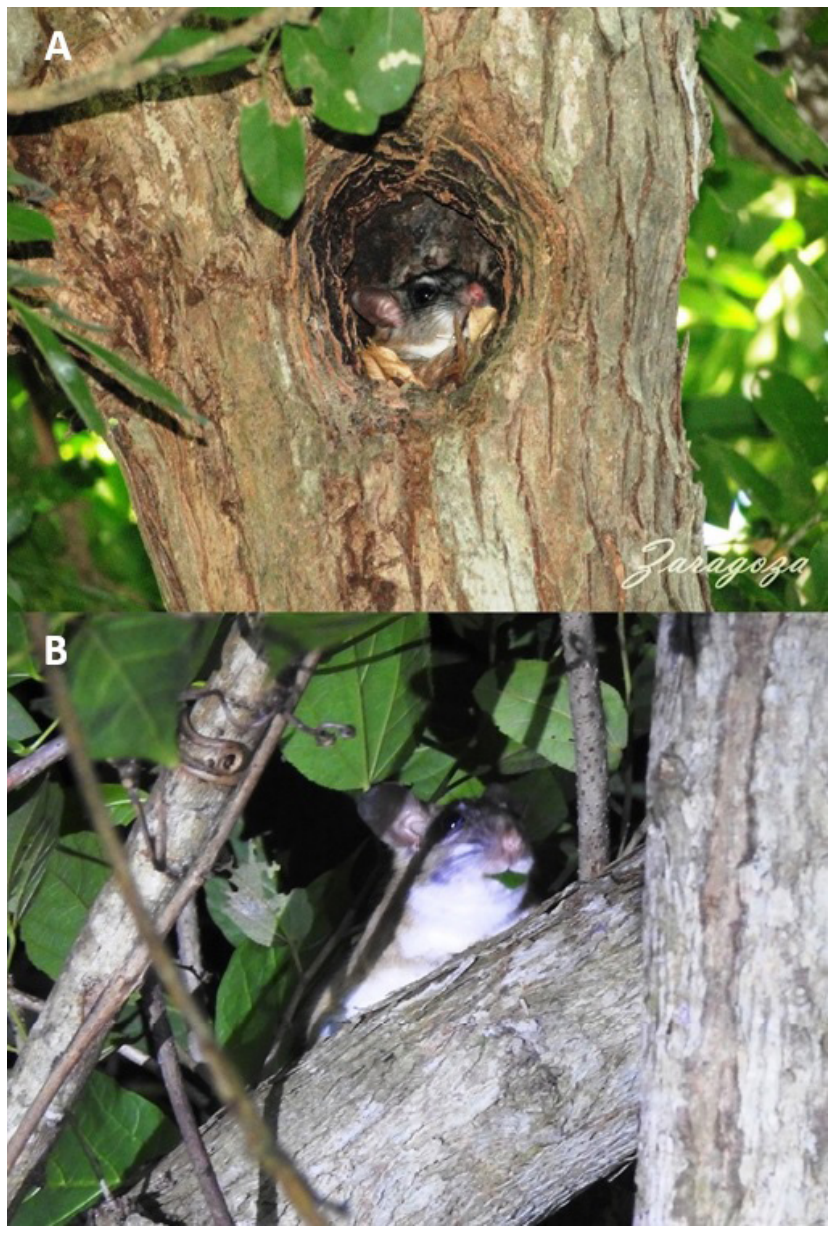

Como la mayoría de los roedores, la rata de Magdalena es de hábitos nocturnos; en ese horario busca su alimento y lleva al cabo actividades de exploración de su territorio (ver figura 8B). Se ha reportado que se encuentra activa de 1 a 1.5 horas después de la oscuridad y hasta la medianoche (Schaldach, 1960: 4). Hasta donde se sabe, es una especie cuyos individuos adultos son solitarios, no forman agrupaciones o colonias. Acostumbran orinar y defecar en letrinas que hacen sobre horquetas y cavidades de los árboles.

Las observaciones de campo indican que su temporada de reproducción es desde el final de la estación seca y durante la temporada de lluvias, lo que comprende finales de mayo hasta noviembre. Estos roedores construyen nidos en forma de esfera entre las ramas de los árboles con hojas, ramitas, pasto y fibras vegetales de plantas como el árbol de la ceiba (Ceiba pentandra; Mendoza, 1997). En cada parto nacen una o dos crías, ciegas, sin pelo, de tonalidad rosada y pesan alrededor de $5 \mathrm{~g}$ (Ceballos y Miranda, 2000: 185). En una ocasión -2229 de mayo de 1970 - se encontró un nido con dos hembras jóvenes que midieron y pesaron, respectivamente, 140 y $141 \mathrm{~mm}$ de longitud total y $17.1 \mathrm{y}$ 18.1 g (López-Forment, Sánchez y Villa, 1971: 103). De manera similar, otro par de crías (hembra y macho) de una selva seca de las cercanías de Chamela, Jalisco, 
Figura 9. Crías de rata de Magdalena encontradas en el estómago de su depredador,

el 18 de octubre de 2016 y convertidas en ejemplares de colección para su preservación y estudio científico (Cervantes,

Vargas, Montaño y Montes de Oca, 2019c). Se incluye un ejemplar hembra adulta para motivos de comparación colectada el 1 de noviembre de 2004. Los tres ejemplares proceden de una selva seca (bosque tropical caducifolio) del estado de Jalisco. que fueron encontradas en el estómago de su depredador -la culebra ratonera: Senticolis triaspis (Hernández, Rodríguez y Jaramillo, 2018)— midieron $171 \mathrm{~mm}$ de longitud total y $20 \mathrm{~g}$ de peso, y $160 \mathrm{~mm}$ y $19 \mathrm{~g}$, respectivamente (ver figura 9).

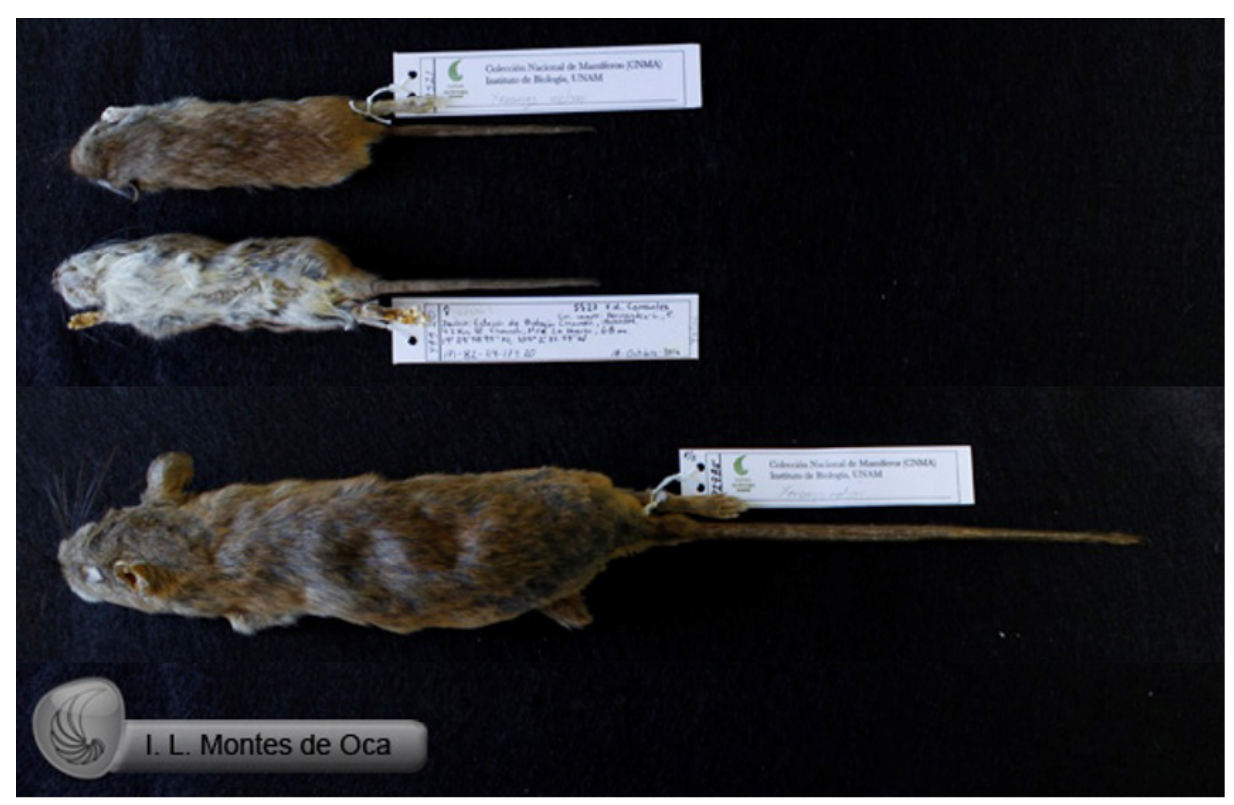

Como especie presa, la rata de Magdalena es de importancia ecológica pues, al igual que la mayoría de los roedores, representa uno de los alimentos principales de diversos reptiles, aves y mamíferos de su ecosistema, lo que ayuda a mantener un equilibrio armónico entre la presencia de animales presa y los depredadores que los consumen.

Xenomys nelsoni no presenta dientes caninos y sus incisivos son de crecimiento continuo, por lo que necesita roer constantemente para gastarlos. Por sus hábitos alimentarios los roedores juegan un papel importante en las comunidades naturales, ya que son de los principales consumidores de plántulas, así como depredadores y dispersores de semillas. Su alimentación es principalmente a base de hojas, yemas y frutos, pero también puede complementarla con insectos y otros invertebrados (Ceballos y Miranda, 2000: 185).

En el área de Chamela, Jalisco, la rata de Magdalena comparte su hábitat con otras especies de roedor. Entre ellos se cuenta la rata arborícola vespertina (Nyctomys sumichrasti), la semiarborícola rata arrocera (Osgoodomys banderanus), el ratón pantanero (Peromyscus perfulvus); y roedores terrestres como el ratón espinoso pintado (Liomys pictus), del que se distingue por su mayor tamaño; en contraste, es de menor tamaño que la rata Hodomys alleni. Por lo tanto, $X$. nelsoni es parte de una rica e interesante comunidad de roedores en las selvas secas. 
Figura 10. A) Comparación de los cromosomas con bandas $G$ de Peromyscus boylii y X. nelsoni. En cada par de cromosomas el de la izquierda es de $P$. boylii mientras que el de la derecha es de $X$. nelsoni (imagen tomada de Haiduk et al., 1988: 400) B) Dendrograma que indica las relaciones de parentesco filogenético de la rata de Magdalena (Xenomys nelsoni; modificado de Longhofer y Bradley, 2006: 965)

\section{Relaciones de parentesco filogenético y genética}

Los escasos estudios que existen sobre $X$. nelsoni se refieren principalmente a datos ecológicos y a temas generales sobre la especie; poco se sabe sobre su origen, historia evolutiva y relaciones de parentesco con otros roedores de su familia (Cricetidae). Sin embargo, estudios comparativos de las estructuras reproductivas entre roedores han permitidosaberque X. nelsoniestá emparentada cercanamente con ratas de bosque, roedores de los géneros Hodomys, Nelsonia y Neotoma, y que forma parte del grupo de especies neotomino-peromyscino. Incluso, se ha dicho que los caracteres únicos de la morfología de Xenomys y Hodomys, en particular de las estructuras reproductivas masculinas, sugieren que el origen de este par de géneros se coloca cerca del ancestro común del numeroso conjunto de especies del género Neotoma, de importante presencia en México (Carleton, 1980: 130). Esta información contribuye de manera importante al conocimiento del origen y evolución de los roedores mexicanos.

A

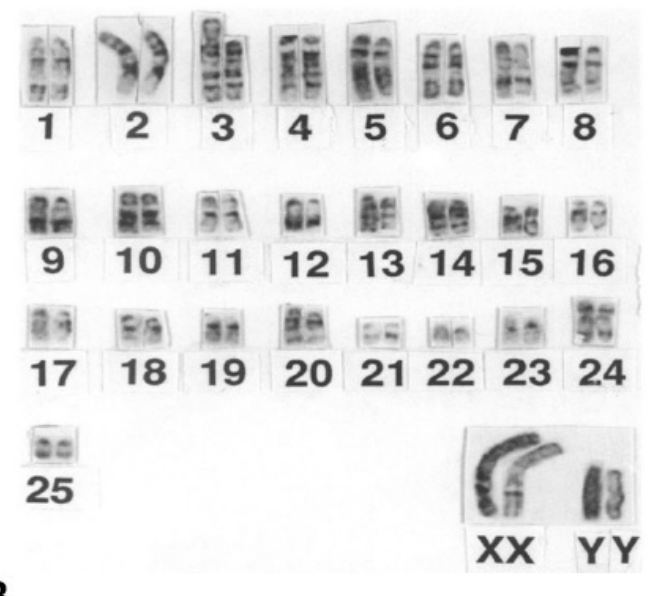

B

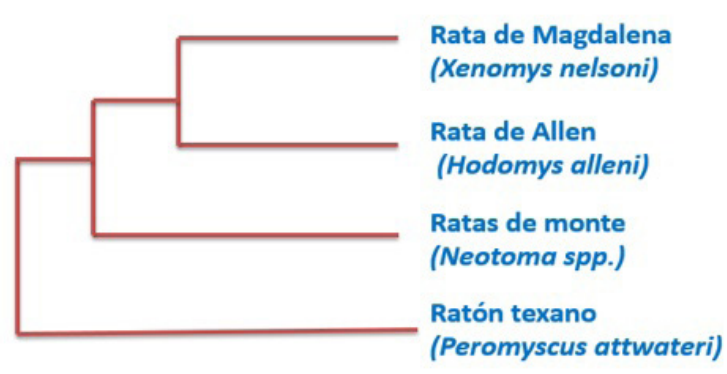

No obstante, otros estudios mostraron queXenomys podría estar más cercano a roedores del género Peromyscus que a Neotoma. El estudio del material genético de la herencia (DNA) de X. nelsoni reveló que este mamífero tiene un número de cromosomas diploide (2n) de 48 (ver figiura 10A). Destaca que comparte con el ratón de los arbustos (Peromyscus boylii) la condición birrámea (un brazo de cada lado del centro del cromosoma) del cromosoma 1, similar al cariotipo de otras especies del género Peromyscus. Esto indica que comparte una ascendencia común con P. boylii en un linaje que posteriormente fue divergente de otros cricétidos (Haiduk, Sánchez y Baker, 1988: 400); por lo tanto, estaría más cercanamente emparentado a Peromyscus que a Neotoma.

Finalmente, ensayos moleculares de secuenciación de genes mitocondriales y nucleares y su análisis filogenético concluyeron que Xenomys está más estrechamente emparentado con Hodomys alleni y el resto de ratas de bosque (Longhofer y Bradley, 2006: 965; ver figura10B). 


\section{Colecciones biológicas}

En la Colección Nacional de Mamíferos (CNMA) del Instituto de Biología, UnAm, actualmente se encuentran varios ejemplares de Xenomys nelsoni preparados en forma convencional para estudio científico. Esto incluye pieles, cráneos, esqueletos y tejidos frescos congelados de ejemplares de cada sexo, de distintas categorías de edad (crías, jóvenes, adultos jóvenes, adultos viejos); ninguna otra colección mexicana contiene ejemplares de este roedor. Estos individuos preservados provienen solamente de la región de Chamela, Jalisco (ver figura 11); haciendo visible que no hay ejemplares disponibles en México de la otra zona donde ha sido registrado, ni reportes recientes publicados de su presencia. Sin embargo, se tiene conocimiento de la existencia de 59 ejemplares de este mamífero depositados en colecciones biológicas norteamericanas (Enciclovida, 2019). Sin duda, esta representación científica debería ser un aliciente para promover la atención a este roedor, al menos, entre la comunidad académica.

Figura 11. Ejemplar hembra de la rata de Magdalena (Xenomys nelsoni) preservado en forma convencional (piel, esqueleto y tejidos congelados), para su estudio científico y custodiado por la Colección Nacional de Mamíferos del Instituto de Biología, UNAM (Cervantes et al., 2016b)

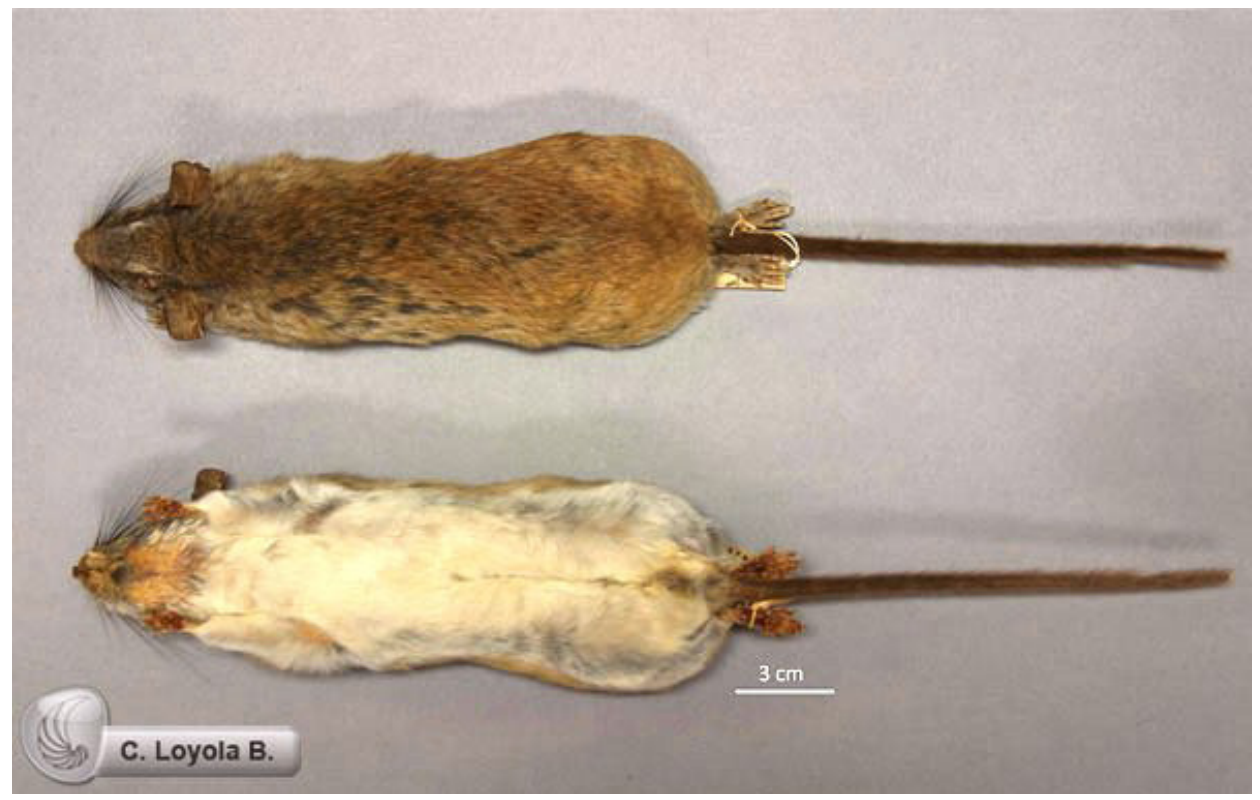

Los ejemplares de colección son evidencias científicas que documentan la biodiversidad. Por lo tanto, son muy valiosos ya que muestran las características de la especie, sus registros de presencia en tiempo y espacio, y el tipo de vegetación a la que se encuentran asociados. Los datos derivados de estos ejemplares son de vital importancia para el conocimiento íntegro de la especie en cuestión y sin esta fuente de información resultaría muy difícil elaborar propuestas completas para su conservación. 


\section{Categoría de riesgo de extinción y conservación}

El gobierno de México considera que la rata de Magdalena se encuentra en la categoría de riesgo de extinción "Amenazada" (Vázquez, 2018). De la misma manera, el organismo International Union for the Conservation of Nature (IUCN) coloca a este roedor en su "lista roja" como "Endangered" (en peligro de extinción; Vázquez, 2018). Su principal amenaza es la destrucción de los bosques tropicales caducifolios o selvas secas (Ceballos y Martínez, 2010: 467), particularmente por el efecto de la fragmentación y pérdida de hábitat debido a la deforestación para la agricultura y el desarrollo (ver figura 12). Gran parte de las selvas secas donde existe $X$. nelsoni se han convertido en plantaciones de cítricos, palmera y plátano, así como áreas de desarrollo para el turismo. Las dos localidades de Colima donde había sido registrada esta especie se han visto gravemente perturbadas, y no se sabe si la rata de Magdalena hoy en día existe allí. Su hábitat en la costa de Jalisco está protegido sólo por la Reserva de la Biosfera Chamela-Cuixmala (Ceballos y Miranda, 2000: 185). Sin duda, es necesario buscar la presencia de este roedor en un área más grande que en la que se le ha registrado actualmente, pues es probable que exista en lugares remotos aún inexplorados. Sin duda, se requieren estudios detallados con validación de campo de modelado de nicho ecológico que conduzcan a la identificación de nuevos registros de su presencia.

Figura 12. La sobrevivencia de la rata de Magdalena (Xenomys nelsoni) en su ambiente natural depende totalmente de la estructura y función apropiadas del ecosistema del bosque tropical caducifolio, donde la presencia del follaje nutrido de los árboles es un elemento indispensable de las selvas secas (fotografía de G. Ceballos, tomada del Banco de Imágenes de la $C O N A B I O)$.

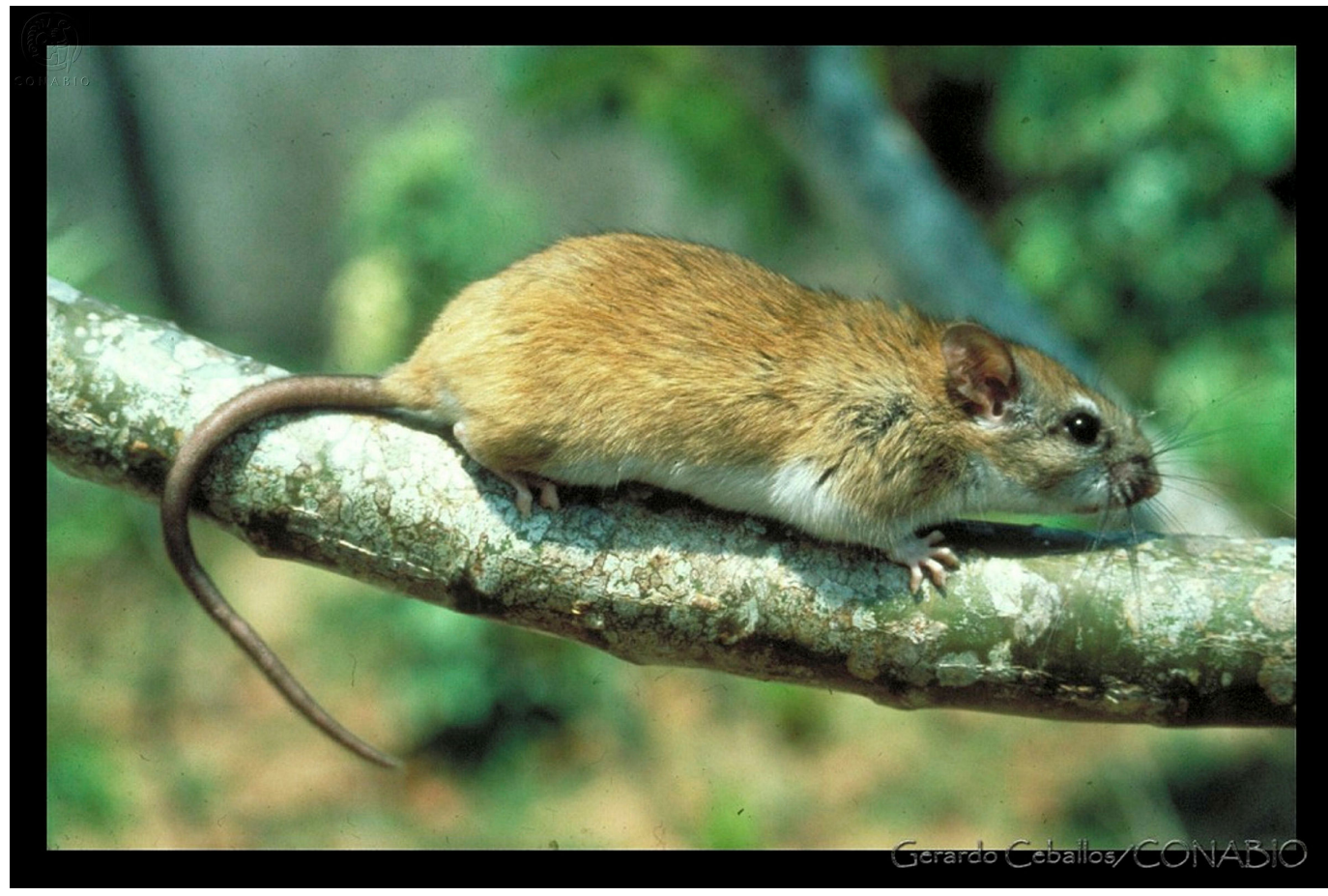

Actualmente, biólogos del Instituto de Biología de la unAm se encuentran investigando diversos aspectos de la historia natural, morfología, genética y evolución de este interesante roedor endémico de México. Sus esfuerzos 
Figura 13. Los resultados del estudio del material genético de la rata de Magdalena (Xenomys nelsoni) en el proyecto internacional Código de Barras de la Vida, en el que participa el Instituto de Biología, UNAM, permitirán distinguir a cada individuo, su sexo y a caracterizar genéticamente a la población a la que pertenece, así como estimar sus niveles de variación genética para motivos de conservación. Las 5 secuencias parciales de la molécula de la herencia

(fragmento 370-400 de 550 pares de bases nucleotídicas de ADN) mostradas corresponden al gen mitocondrial Citocromo Oxidasa subunidad I, información central para la elaboración del Código de Barras de ADN. involucran conocer detalles sobre su tamaño y forma; su estructura craneal y poscraneal. Asimismo, examinan molecularmente muestras de tejidos de individuos de distintas localidades para su identificación molecular; y comparan la variación genética entre grupos de individuos (ver figura 13). Con evidencias morfológicas y genéticas se busca conocer el origen evolutivo de la especie y entender sus relaciones de parentesco con otras especies afines de roedores. Los resultados generados y la difusión de los mismos seguramente contribuirán a su conocimiento integral y a planear acciones para su conservación.

\section{CÓDIGO DE BARRAS DE ADN}

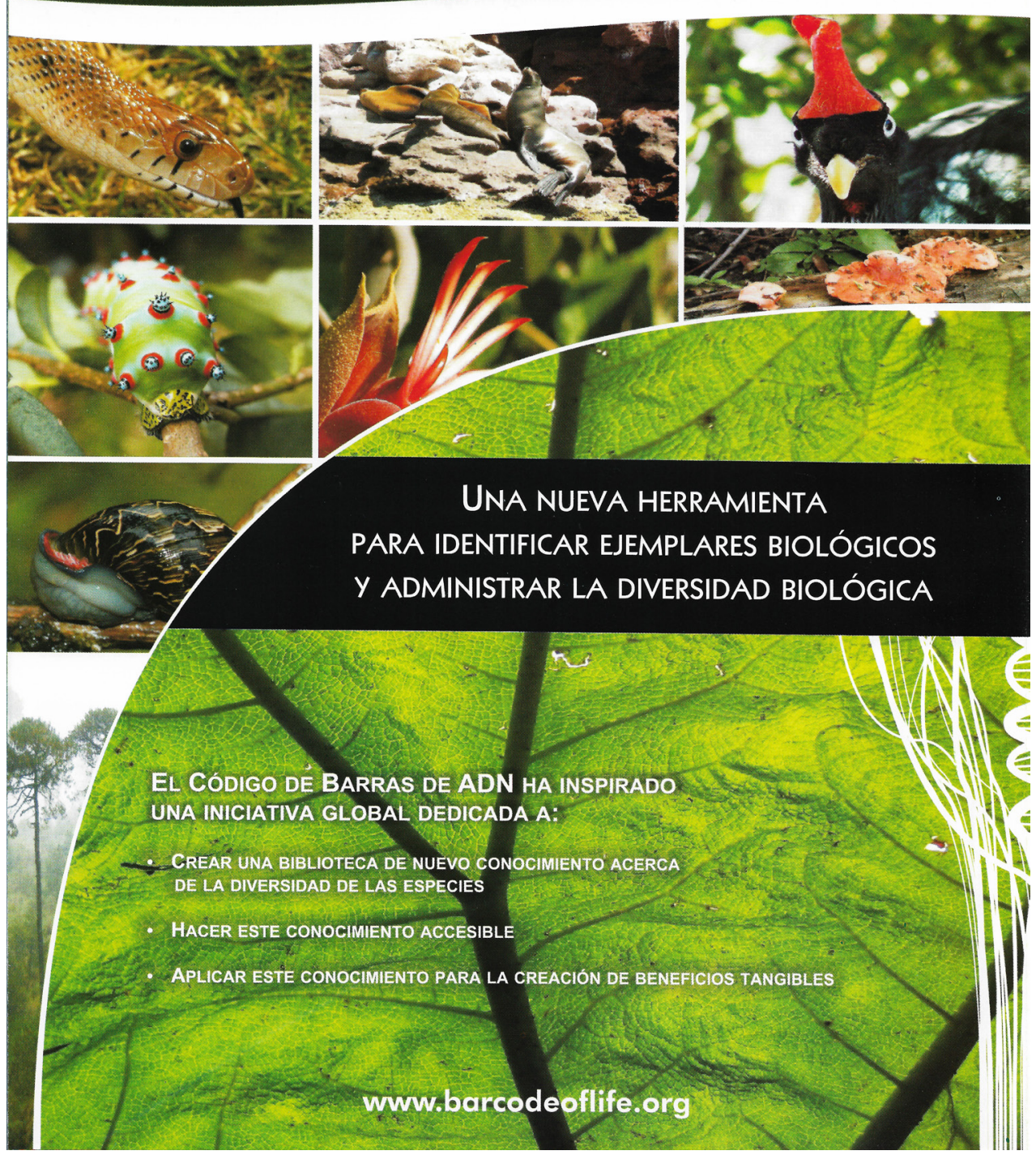


"Rata de Magdalena: un importante mamífero mexicano, poco conocido y en riesgo de extinción"

Sin embargo, es necesario que un mayor número de personas participen en la divulgación de la existencia y conocimiento de este mamífero pequeño único de México y de importancia en la estructura y función de las selvas secas; sobre todo, difundir información sobre el riesgo de extinción en que se encuentra. Afortunadamente, la presencia de esta especie en un área natural protegida como Reserva de la Biosfera, ya es una condición favorable para la protección de sus poblaciones al promover la disponibilidad de su hábitat en condiciones naturales inalteradas de las selvas secas.

\section{Conclusiones}

La rata de Magdalena (X. nelsoni) es una especie única de México, de relevancia para el ecosistema en el que habita. Desafortunadamente se trata de una especie en riesgo de desaparición. Por lo tanto, se debe fomentar su estudio y efectuar acciones para que sea del conocimiento de la sociedad. Es necesario que comunidades locales, académicos y estudiantes, organizaciones no gubernamentales y los sectores del gobierno interactúen y diseñen a la brevedad acciones orientadas a la conservación de este mamífero. En consecuencia, las expectativas para la supervivencia de este interesante mamífero dependerán de los esfuerzos que se inviertan en su conocimiento y conservación.

\section{Agradecimientos}

Dedicamos esta contribución con respeto y admiración al Dr. Jorge Humberto Vega Rivera, amigo y colega, por su brillante y significativa labor en beneficio de la Estación de Biología Chamela (EBC) del Instituto de Biología, unAm. Su intenso trabajo e inquebrantable actitud universitaria al frente de esa área natural protegida impactaron favorablemente el estudio y protección de la biodiversidad de la región, la formación académica de numerosos estudiantes y la divulgación del conocimiento sobre las selvas secas. Agradecemos la ayuda de Susana Guzmán Gómez para subir información e imágenes al portal IREKANI.

\section{Referencias}

- Bullock, S. H. y Solís, A. (1990). Phenology of canopy trees of a tropical deciduous forest in Mexico. México. Biotropica, 22(1), 22-35.

* Carleton, M. D. (1980). Phylogenetic relationships in neotomine peromyscine rodents (Muroidea) and a reappraisal of the dichotomy within New World Cricetinae. Miscellaneous Publications Museum of Zoology, University of Michigan, 157, 1-146. Recuperado de: https://deepblue.lib.umich.edu/bitstream/ handle/2027.42/56401/MP157.pdf? sequence=1\&isAllowed=y.

- Ceballos, G., y Miranda, A. (2000). A field guide to the mammals from the Jalisco coast. Fundación Ecológica de Cuixmala-UnAM. Recuperado de: http://www.ecologiaunam.com.mx/wp-content/uploads/2016/02/2000-Gu\%C3\%ADa-de-Campo-delos-Mam\%C3\%ADferos-de-la-Costa-de-Jalisco.pdf. 
"Rata de Magdalena: un importante mamífero mexicano, poco conocido y en riesgo de extinción"

* Ceballos, G., Martínez, L., García, A., Espinoza, E., Bezaury, J. y Dirzo, R. (2010). Mamíferos. En Ceballos, G. y Martínez, L. (eds.), Diversidad, amenazas y áreas prioritarias para la conservación de las Selvas Secas del Pacífico de México (pp. 119144). México, D.F.: Fondo de Cultura Económica y Comisión Nacional para el Conocimiento y Uso de la Biodiversidad.

* Cervantes, F. A. y Arriaga, S. (2010a). Cráneo de la rata arborícola Xenomys nelsoni [vista dorsal]. En Irekani, registro no. 8634, Instituto de Biología, UNAM. Recuperado de: http://unibio.unam.mx/irekani/handle/123456789/12687?proyecto=Irekani.

* Cervantes, F. A. y Arriaga S., (2010b). Cráneo de la rata arborícola Xenomys nelsoni [vista ventral]. En Irekani, registro no. 8635, Instituto de Biología, UNAM. Recuperado de: http://unibio.unam.mx/irekani/handle/123456789/12681?proyecto=Irekani.

* Cervantes, F. A. y Hernández R., (2016a). Vista dorsal comparativa de pieles de ejemplares de museo de roedores de la tribu Neotomini, familia Cricetidae. En Irekani, registro no. 12091, Instituto de Biología, UNAM. Recuperado de: http:// unibio.unam.mx/irekani/handle/123456789/70419?proyecto=Irekani.

* Cervantes, F. A. y Hernández, R. (2016b). Piel de un ejemplar de museo de la rata de Magdalena Xenomys nelsoni. En Irekani, registro no. 12101., Instituto de Biología, UNAM. Recuperado de: http://unibio.unam.mx/irekani/handle/123456789/70423? proyecto=Irekani.

* Cervantes, F. A., Castañón, C., Sánchez, J., Vargas, J. y Hortelano, Y. (2016). Tercer molar inferior derecho de un ejemplar adulto de la rata de Magdalena Xenomys nelsoni. En Irekani, registro no. 11911, Instituto de Biología, UNAM. Recuperado de http://unibio.unam.mx/irekani/handle/123456789/37949?proyecto=Irekani.

* Cervantes, F. A., Ramos, K., Vargas, J. y Montaño, P. (2019a). Ejemplar macho de la Rata de Magdalena (Xenomys nelsoni) en cautiverio. En Irekani, registro no. 12622, Instituto de Biología, UNAM. Recuperado de: http://unibio.unam.mx/irekani/hand le/123456789/71436?proyecto=|rekani.

* Cervantes, F. A., Ramos, K., Vargas, J. y Montaño, P. (2019b). Ejemplar macho de la Rata de Magdalena (Xenomys nelsoni) capturado durante el verano. En Irekani, registro no. 12623., Instituto de Biología, UNAM. Recuperado de: http://unibio.unam. mx/irekani/handle/123456789/71437? proyecto=Irekani.

* Cervantes, F. A., Vargas, J., Montaño, P. y Montes de Oca, I. (2019c). Crías y hembra adulta de la rata de Magdalena (Xenomys nelsoni). En Irekani, registro no. 12624, Instituto de Biología, UNAM. Recuperado de: http://unibio.unam.mx/irekani/handl e/123456789/71435?proyecto=Irekani.

* Enciclovida. (2019). Rata de Magdalena (Xenomys nelsoni) Recuperado de: http:// enciclovida.mx/especies/34397-xenomys-nelsoni.

* Haiduk, M., Sánchez C.y Baker, R. (1988). Phylogenetic relationships of Nyctomys and Xenomys to other cricetine genera based on data from G-banded chromosomes. En Southwestern Naturalist 33(4), 397-403. 
"Rata de Magdalena: un importante mamífero mexicano, poco conocido y en riesgo de extinción"

* Hayden, B., Greene, D. F.y Quesada, M. (2010). A field experiment to determine the effect of dry-season precipitation on annual ring formation and leaf phenology in a seasonally dry tropical forest. En Journal of Tropical Ecology, 26(2), 237-242.

* Hernández, P., Rodríguez, A. y Jaramillo, J. (2018). Depredación del roedor Xenomys nelsoni por la serpiente Senticolis triaspis en la región de Chamela, Jalisco, México. XIV Congreso Nacional de Mastozoología, Universidad Autónoma de Yucatán y Asociación Mexicana de Mastozoología. Mérida, Yucatán.

* López-Forment C. W., Sánchez, C. y Villa, B. (1971). Algunos mamíferos de la región de Chamela, Jalisco, México [Anales del Instituto de Biología. Universidad Nacional Autónoma de México]. Serie Zoología, 42(1), 99-106.

- Longhofer, L. K. y Bradley, R. 2006. Molecular Systematics of the genus Neotoma based on DNA sequences from intron 2 of the alcohol dehydrogenase gene. Journal of Mammalogy, 87(5), 961-970.

* Mendoza, A. (1997). Heterogeneidad ambiental, dinámica de poblaciones y estructura de comunidades de pequeños mamíferos en una selva tropical caducifolia [tesis de Maestría, Facultad de Ciencias, UNAM].

- Noguera, F., Vega, J., García, A. y Quesada, A. (2002). Xenomys nelsoni Merriam 1892. En Noguera, F. A., Vega Rivera, J. H., García Aldrete. A. N. y Quesada Avendaño, M. (eds.), Historia Natural de Chamela (p. 439). México, D. F.: Instituto de Biología e Instituto de Ecología, UNAM.

* Schaldach, W. (1960). Xenomys nelsoni Merriam, sus relaciones y sus hábitos. Revista de la Sociedad Mexicana de Historia Natural, 21 (2), 425-434.

* Tzab Hernández, L. A. y Macswiney González, M. C. (2014). Roedores ¿plagas indeseables o animales útiles? CONABIO. Biodiversitas, 115:12-16.

- Vázquez, E. (2018). Xenomys nelsoni. The IUCN Red List of Threatened Species 2018. Recuperado de: https://www.iucnredlist.org/search?query=xenomys\%20 nelsoni\&searchType $=$ species.

\section{Cómo citar este artículo}

* Cervantes Reza, Fernando A. y Montaño Sosa, Pamela (2019). Rata de Magdalena: un importante mamífero mexicano, poco conocido y en riesgo de extinción. Revista Digital Universitaria (RDU). Vol. 20, núm. 5 septiembre-octubre. DOI: http:// doi.org/10.22201/codeic.16076079e.2019.v20n5.a2.

Recepción: 27/03/2019. Aprobación: 03/07/2019 